\title{
Transsubjectivity
}

\section{DAVID HitchCOCK}

Department of Philosophy

McMaster University

Hamilton, $O N$

Canada L8S 4L8

hitchckd@mcmaster.ca

\begin{abstract}
I describe and evaluate Harald Wohlrapp's proposal in The Concept of Argument that we should see reasonable argumentation as guided by the "principle of transsubjectivity ... that, beginning with my subjectivity, I put my actual ego up for consideration as well as heighten and transcend it by seeking to participate in a general human potential, which is only attainable by recognizing the subjectivity of the Other", and thus as having a quasi-religious meaning.
\end{abstract}

Résumé: Je décris et j'évalue la proposition de Harald Wohlrapp dans The Concept of Argument que nous devrions voir l'argumentation raisonnable comme étant guidée par le «principe de la transsubjectivité ... selon lequel je commence par ma subjectivité, je mets mon ego en considération, je le rehausse et le transcende en cherchant à participer à un potentiel humain général, qui ne peut être atteint qu'en reconnaissant la subjectivité de l'Autre » et donc comme ayant une signification quasi religieuse.

Keywords: argumentation, framing, Harald Wohlrapp, reasonable argumentation, religion, subjectivity, transsubjectivity

\section{Introduction}

In the last chapter of The Concept of Argument, Harald Wohlrapp (2014/2008) proposes that we see reasonable argumentation as guided by what he calls "the principle of transsubjectivity". To see argumentation in this way, he argues, is to find in it a quasi-religious meaning. The faith in human reason embodied in reasonable argumentation, the faith that by reasoning together we will work out how to do things in the right way, is a secular counterpart of a religious faith in an ultimate union with God. "...Argumentative speech," he writes, "...has a transcendent core. It expresses a strong, quasi-religious belief in humanity's spiritual and ethical potential." (p. 304)

In what follows, I propose first of all to make this point of view understandable. To do so requires making clear Wohlrapp's key concepts of framing, argumentation, subjectivity, reasonable argumentation, and the principle of transsubjectivity. 
With these concepts in place, we can then appreciate how reasonable discussants can be seen as trying to transcend their subjectivity, and so how argumentative speech can be seen as having a transcendent core and as reflecting a quasi-religious faith in human reason.

Having clarified Wohlrapp's proposal in this way, I shall make some brief evaluative remarks about it.

\section{Framing}

To see reasonable argumentation as guided by the principle of transsubjectivity is a kind of framing. It is not an additional characteristic of argumentation, but a way of seeing it. Framing as Wohlrapp understands it is a ubiquitous phenomenon of human subjectivity, one of which we are usually unconscious. We see $B$ as $A$, for a host of different values of the variables ' $B$ ' and 'A'. Generally, we take ourselves to be seeing B as it really is, not realizing that we are unconsciously framing it in a certain way. For example, we might see a car that we own as a status symbol, as a private space, or just as a means of transportation (Wohlrapp 2014/2008, pp. 177-178) -without being fully conscious of how we are framing it and how it might be framed differently. In general, the way we frame issues and phenomena is not a conscious decision on our part. Thus there is something unusual in Wohlrapp's proposal that we frame reasonable argumentation in a certain way. Framing B as A is not usually a deliberate, conscious decision taken as the result of being convinced by an argument for doing so. But perhaps Wohlrapp's proposal can be construed as a proposal to recognize explicitly a way of seeing reasonable argumentation that is already implicit to some extent in those who practice it and are committed to it.

Wohlrapp's proposal to frame reasonable argumentation as guided by the principle of transsubjectivity is supposed to be compatible with different theories of argumentation using different sets of concepts and principles, not just with the complex theoretical construction of his book. Nevertheless, his proposal depends on certain features of his understanding of what constitutes reasonable argumentation. In describing those features, I shall avoid the distinctive terminology of his theory, so as to make his proposal more understandable to those who are unfamiliar with his terminology or who theorize differently about argumentation. 


\section{Argumentation}

To begin with, we need to be aware that Wohlrapp uses the word 'argumentation' as a name for the practice in which dialogue partners discuss a thesis with a view to determining whether it is suitable as a new guide for action and reflection (pp. lix, 132, 270). ${ }^{1}$ In his book, he uses four main examples of such "argumentation":

- the case made by Cristóbal Colón (Christopher Columbus) in 1492 for financing his voyage across the Atlantic that led to the European discovery of the New World,

- the debate in the French parliament in 1792 and 1793 that led to the decision to execute the former king (Louis $\mathrm{XVI}$ ) and thus complete the transition from a monarchy to a republic,

- the controversy over the supposed heat substance phlogiston at the beginning of the rise of modern chemistry in the 18 th century, and

- the contemporary debate over genetic modification in food production and in medicine.

Argumentative discussions like those just mentioned concern issues about which the participants do not yet have knowledge or access to knowledge, but cannot rely on mere subjective opinion. The issues are serious, and participants who are being reasonable put their trust in the back and forth of claims, justifications and criticisms as the best way to come to a conclusion that is suitable as a guide for action and reflection.

\section{Subjectivity}

A second precondition for Wohlrapp's proposal is an acknowledgement of the subjectivity that reasonable argumentation is to be seen as trying to transcend. For an adequate theory of argumentation, Wohlrapp holds, one needs a richer understanding of what it is to be a subject than either the rhetorical notion of an audience to be persuaded or the dialectical notion of an interloc-

\footnotetext{
${ }^{1}$ I use the phrase 'guide for action and reflection' as a replacement for Wohlrapp's word 'orientation', which he defines as a "theory that symbolically represents practically relevant distinctions, relationships, and regularities" ( $p$. 108). In a previous version of this article, I used 'basis for acting' as a replacement for 'orientation'. Wohlrapp objected that this paraphrase treated an orientation as too exclusively a guide to action.
}

(C) David Hitchcock Informal Logic, Vol. 37, No. 3 (2017), pp. 230-239. 
utor who gives or withholds assent. To be a subject is to subscribe to a system of guides for action and reflection, whose guidance is manifested both in one's actions and practices and in the value that one attaches to the pursuit of one's goals. This guidance system is the cognitive part of a person that binds from within the person's characteristic ways of acting, thinking, speaking and arguing. It has an objective component, in that it takes into account external conditions, including other people. Thus the theories that guide a person come with a claim to being suitable as guides. In argumentation a thesis is advanced as suitable to fill a gap in the guidance systems of the participants. The participants in the discussion thus need to consider how the thesis fits with their own guidance system and to be prepared to change it. They can do so because each person is aware to some extent of the system of theories to which they subscribe and can increase that extent, especially in interaction with others.

At the deepest level, to be subjective involves living within the way one sees issues and states of affairs - ways of seeing of which one is typically unaware and that taken together constitute a more or less coherent world-view. Every human being is subjective in this sense, and cannot escape being so. None of us can acquire a "God's eye view" in which we see the world sub specie aeternitatis, viewing it from nowhere. The sense in which we transcend our subjectivity in reasonable argumentation is thus not a matter of somehow becoming objective. No human being is ever objective in the sense of lacking a personal, situated way of seeing things.

\section{Reasonable argumentation}

A third pre-condition is acceptance of something like Wohlrapp's account of what it is to be reasonable in argumentation. He takes pains to distinguish what he has in mind from standard accounts of what he calls by contrast "rational argumentation" (p. 394). So-called "rational argumentation" is confined to logical inferences from clear premisses, calculations of probability, and exercises of instrumental rationality-for example, in a proof that there is no largest prime number, in calculations of the risk that a child conceived by two people will have a disease for which each person carries the gene, and in calculating the quickest way to get to a desired destination. Such a restricted normative framework ignores the dynamic and subjective dimensions of discussion of theses advanced to fill a gap in the theories on which we rely to make our way in the world. When 
there is this sort of gap, we often lack the precise and stable concepts required for logical inference, the factual knowledge needed to calculate probabilities, and the agreement on goals needed to apply canons of instrumental rationality. Further, we are subjective, in the sense of being personally engaged with the issue at hand, with more or less strong commitments. So-called "rational argumentation" ignores this subjective dimension and thus is unduly restricted. Realism requires that we incorporate subjectivity in our account of reasonable argumentation.

Without further qualification, however, incorporating subjectivity can license oratorical persuasiveness as the supreme canon of reasonable argumentation. Wohlrapp avoids this unpalatable consequence by rejecting the idea that the goal of participation in argumentation is to persuade the others to accept one's position. Rather, the goal is to determine jointly whether a thesis is suitable as a new guide for action and reflection. Consider (my example) the individuals and organizations that put forward a "vulnerable persons standard" as a means of protecting the lives of vulnerable persons who they feared might experience coercion and abuse once physician-assisted dying became legal in Canada (http://www.vps-npv.ca/readthestandard). Their standard was not just an expression of their personal opinion. They proposed it as a set of safeguards of vulnerable persons to be incorporated in federal legislation regulating physicianassisted death. By publishing their proposal in a public forum, and by providing justifications for the safeguards that they proposed, they invited commentary and implicitly indicated a readiness to respond to objections and criticisms. They externalized as an object to be considered by others their framing of physician-assisted dying as a threat to the lives of vulnerable persons. They thus opened themselves up to reconsideration of their proposal in the light of objections, a reconsideration that might involve a change in their own subjectivity, in how they see themselves and how they see the world. Likewise, those who frame physician-assisted death as a blessed relief for intolerable and irremediable suffering might have been led to change their views of themselves and of the world by considering seriously the proposed vulnerable persons standard and the arguments for it.

Reasonable argumentation is thus both subjective and dynamic. It requires treating the Other with whom one discusses a proposed thesis as an equal. If a thesis is up for discussion, it is unreasonable for its proponent to decline to provide a justification. If an objection is raised, it is unreasonable to ignore it. Such reactions may reflect self-confidence about the rightness of 
one's own position or the arrogance of holding a position of power. Whatever the cause, the failure to respond to the Other who requests a justification or raises an objection is according to Wohlrapp a failure to recognize the Other as an equal partner. In contrast, the recognition of the Other that reasonableness requires puts one's own subjectivity up for consideration. Why does one take such a risk? One wants to find out whether a thesis that has been advanced is suitable as a new guide for action and reflection. The Other with whom one is in dialogue is a source of information, opinions and ways of seeing that one does not have oneself and that can help in getting to a conclusion that is supported by an adequate justification with an adequate response to objections and criticisms.

\section{Transsubjectivity}

To sum up, Wohlrapp's proposal to see reasonable argumentation as guided by what he calls the principle of transsubjectivity rests on the following three assumptions about argumentation:

- Argumentation is to be understood as a practice of investigating in dialogue whether a thesis is a suitable as a new guide for action and reflection in an area where we do not have knowledge.

- In this practice, the subjectivity of the participants is engaged, in the exposure to discussion by Others of the system of theories by which each of them guides their action and reflection.

- Reasonable argumentation requires that we recognize our dialogue partners as equals, in the sense that we satisfy their requests for justification and respond to their objections and criticisms, thus opening ourselves to changes in our position and in the way we see things, i.e. to changes in our subjectivity.

What then is the principle of transsubjectivity that we are invited to see as guiding reasonable argumentation as so understood? Wohlrapp takes the notion of such a principle from his teacher Paul Lorenzen, who coined the word 'transsubjectivity' as an abbreviation for 'transcendence of subjectivity' (Lorenzen 1969 , p. 82). In his John Locke lectures at the University of Oxford in 1967-68, Lorenzen lays down the principle "Let us transcend our subjectivity!" as the fundamental principle of reason and morality: He explains the prescribed transcendence as 
still subjectivity, but a subjectivity which is aware of its own limits-and tries to overcome them. Transsubjectivity is not a fact, but it is not a postulate either. Transsubjectivity is simply a term characterizing that activity in which we are always already involved if we begin to reason at all. (Lorenzen 1969, p. 82)

To be subjective, for Lorenzen, is to be unwilling to surrender one's own opinions. To be transsubjective is not to cease to be a subject, which is impossible. Rather, it is to try to overcome the limitations of one's opinions.

Wohlrapp's conception of transsubjectivity deepens and socializes Lorenzen's idea. Wohlrapp articulates as a contrast concept what he calls "the principle of subjectivity" (pp. 397398), according to which we organize things so as to control the conditions under which we live and thus make it possible to act as we like. He sees human beings in the advanced industrial economies as living by this principle, with a self-confidence that is shaken only by such things as illness and death. This selfconfidence is an illusion. Secular people in the modern world have lost the sense of trust and the level of meaning formerly provided by religion. As Wohlrapp puts it, "mere subjective self-determination devours meaning." (p. 398, translation modified) But trust is still required. "Self-determination without trust is barren and empty." (p. 398)

The contrasting transsubjectivity that Wohlrapp finds in reasonable argumentation is not mere inter-subjective agreement. It is

a heightening of subjectivity aimed at the potential for being compatible with the subjectivity of the Other...beginning with my subjectivity, I put my actual ego up for consideration as well as heighten and transcend it by seeking to participate in a general human potential, which is only attainable by recognizing the subjectivity of the Other. (p. 401)

By engaging in reasonable argumentation, we manifest a trust that we will work out together a suitable new guide for action and reflection, one that transcends the limited basis from which each of us individually begins.

\section{Religion}

What, we might wonder, does all this have to do with religion? 
fest a trust in the power of reason that is akin to the trust of a traditional religious believer in the providence of a loving God, and we aim for a transcendence of our subjectivity that is a horizontal analogue of the vertical transcendence postulated by theism. In each case, there is something beyond me. But the trust and transcendence in reasonable argumentation may hardly seem religious.

Whether it is in fact religious, or quasi-religious, depends of course on what we mean by religion. Wohlrapp articulates his thinking on this question in the last section of his book and at greater length in (Wohlrapp 2010). He notes that religions have a practical side and a theoretical side - on the practical side such things as prayers and sacrifices, on the theoretical side texts about the holy, about gods, about God. To treat the messages of the theoretical side as cognitive claims to be adjudicated by philosophical argument is to miss what is central to religion. What is really important, from the pragmatic point of view that Wohlrapp shares with Peirce, is religious practice: prayers, worship, and observance of prescribed rules. If one gets accustomed to such a practice, Wohlrapp thinks, one may come to "the substance of religion...the encompassing trust that the world is good and right" (Wohlrapp 2014/2008, p. 414).

Wohlrapp sketches the development of this trust. A child is born with a "basic trust" that loving parenting strengthens into a sense that the world is good and right. A religious community heightens this "natural religiosity" into true religious consciousness.

In the development of our species, however, advances in technical knowledge have made outmoded the archaic belief that the forces of nature are divine. The Enlightenment replaced the promise of salvation with a belief in progress, which however the horrors of the 20th century have subsequently undermined. We are left with a tension between the enlightened secular part of humanity and the believers in traditional religion who are not touched by enlightenment. In reasonable argumentation, however, enlightened people can find a transcendent meaning, a sense that things are good and right, through their trust in human reason-a trust analogous to the trust that according to Wohlrapp is the substance of religion.

In a coda to his article on the definition of religion, Wohlrapp asserts (2010, p. 407) that the alpha and omega of religion is the posture or operation of distancing: remaining aware that one's consciousness is provisional and always to be renewed and improved. We find this distancing, he holds, in the transcendent engagement with others in the practice of reasonable 
argumentation guided by the principle of transsubjectivity. Reasonable argumentation thus has a quasi-religious meaning.

\section{Evaluative remarks}

We should note first that Wohlrapp has quite legitimately singled out for theoretical attention under the name 'argumentation' an important human practice, one that investigators of argumentation often lump indiscriminately with less significant activities. He is right to note the way that our subjectivity is engaged when we reason together about important issues that our present knowledge cannot settle. He rightly notes the combination of distancing and commitment in the participants in such discussions. Each of us has a commitment to our position, but by expressing it publicly and providing a justification we invite criticisms and requests for further justification, hoping that the contributions of others will help us get to a conclusion on which we can justifiably rely. Wohlrapp is thus right to see in the practice of argumentation an implicit trust in the power of human reason. We can indeed see reasonable argumentation as guided by the principle that we ought to transcend our subjectivity, in the sense of making our subjectivity compatible with the subjectivity of others. It is no criticism of these claims to note that reality falls far short of the ideal, that (for example) argumentation in our political life and in social media is full of irrelevant personal attacks.

But does the trust in human reason implicit in reasonable argumentation really give it religious meaning? Not in the full sense, I would argue. Central to all religions is a promise of personal salvation, whether in the release from suffering available to those who follow the Eightfold Way of atheistic Buddhism or the ultimate union with God promised by theistic and polytheistic religions like Judaism, Christianity, Islam and Hinduism. Further, they have rituals to mark, and give significance to, the birth, maturation, marriage, and death of individual adherents. There is nothing like this in the trust in human reason implicit in reasonable argumentation. Nor is it reasonable to expect it. The trust in human reason that reasonable argumentation reflects is not a trust that things are good and right for me, but a trust that things are good and right in general, i.e. for us human beings who participate in the practice.

Secular human beings can still believe in "humanity's spiritual and ethical potential" (Wohlrapp 2014, p. 394), but may not be able to actualize this potential to the same extent as 
adherents to traditional religions think they can. Further, as Wohlrapp may well agree, it is not only in reasonable argumentation that secular humanity can realize its spiritual and ethical potential. It can do so as well, and perhaps to a greater extent, in the care that one human being has for others, whether they are those near and dear or strangers whose plight moves one to help. Argumentation is a practice that helps us to make our way in the world. To seek in it a secular counterpart to the meaning provided by religion is both to expect too much of argumentation and to grant too little to religion.

\section{Summary}

In The Concept of Argument (2014/2008) Harald Wohlrapp proposes that we see reasonable argumentation as guided by what he calls "the principle of transsubjectivity" and thus as having a quasi-religious meaning. To make this proposal understandable, I have explained Wohlrapp's conceptions of framing, argumentation, subjectivity, reasonable argumentation, transsubjectivity and religion. While Wohlrapp rightly sees reasonable argumentation as conforming to an imperative to transcend our subjectivity, it is an exaggeration to describe its implicit trust in the power of human reason as religious.

\section{References}

Kant, Immanuel. (2008). Groundwork for the metaphysics of morals, trans. Jonathan Bennett. Available at http://www.earlymoderntexts.com/assets/pdfs/kant1785.pdf; accessed 2016/03/24. German original first published in 1785.

Lorenzen, Paul. (1969). Normative logic and ethics. Mannheim: Bibliographisches Institut.

Wohlrapp, Harald. (2010). Eine pragmatische Definition der Religion. In In Sprachspiele verstrickt, oder: Wie man der Fliege den Ausweg zeigt: Verflechtungen von Wissen und Können, eds. Stefan Tolksdorf and Holm Tetens, 379-407. Berlin: de Gruyter.

Wohlrapp, Harald R. 2014. The concept of argument: A philosophical foundation. Dordrecht: Springer. German original first published in 2008. 